\title{
Morphotaxonomy- and metabarcoding-based ecological assessment of Cyprus streams' diatom communities and correlation with environmental and anthropogenic influences
}

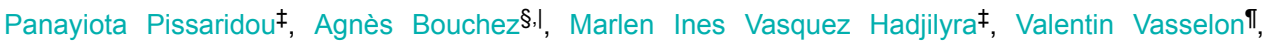

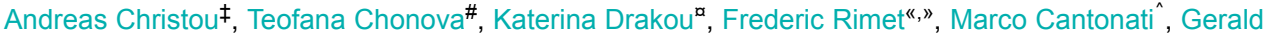 \\ Dörflinger ", lakovos Tziortzis ${ }^{v}$ \\ $\ddagger$ Cyprus University of Technology, Limassol, Cyprus \\ § INRAE CARRTEL, Thonon-les-bains, France \\ I USMB CARRTEL, Thonon-les-bains, France \\ II Scimabio Interface, Thonon Les Bains, France \\ \# INRAE, Thonon Les Bains, France \\ a Cyprus University of Technology, Nicosia, Cyprus \\ «INRAE, UMR CARRTEL, Thonon, France \\ » INRA, UMR CARRTEL, Thonon, France \\ ${ }^{\wedge}$ Museo delle Scienze - MUSE, Trento, Italy \\ Water Development Department, Nicosia, Cyprus
}

\begin{abstract}
Corresponding author: Panayiota Pissaridou (panayiota.pissaridou@cut.ac.cy), Marlen Ines Vasquez Hadjilyra ( marlen.vasquez@cut.ac.cy)
\end{abstract}

Received: 24 Feb 2021 | Published: 04 Mar 2021

Citation: Pissaridou P, Bouchez A, Vasquez Hadjilyra MI, Vasselon V, Christou A, Chonova T, Drakou K, Rimet F, Cantonati M, Dörflinger G, Tziortzis I (2021) Morphotaxonomy- and metabarcoding-based ecological assessment of Cyprus streams' diatom communities and correlation with environmental and anthropogenic influences. ARPHA Conference Abstracts 4: e64962. https://doi.org/10.3897/aca.4.e64962

\begin{abstract}
In freshwater ecosystems, periphytic biofilms include diatom assemblages that depend on environmental conditions (e.g., nutrient concentrations, salinity, temperature etc.). These assemblages respond rapidly to environmental changes, which makes diatoms valuable bioindicators. For this reason, they are currently used in freshwater biomonitoring programs (e.g., EU Water Framework Directive - WFD) (Foster et al., 2000). To date, diatom taxonomic identification is based on morphological criteria, which requires high
\end{abstract}


taxonomic expertise to identify them to the species level needed for biomonitoring. Having this in mind, new strategies have been examined for the development of high-throughput, non-biased identification approaches. Human activities are the leading cause of environmental impairments and appropriate biomonitoring of ecosystems is needed to effectively assess the impact of their activities. In the last ten years, DNA metabarcoding combined with next-generation sequencing and bioinformatics, have been proposed as a complementary approach to morphological identification. In the past ten years, DNA metabarcoding coupled with next-generation sequencing and bioinformatics represents a complementary approach for diatom biomonitoring (Vasselon et al., 2019). In this study, this approach was used for the first time in Cyprus considering the association of environmental and anthropogenic pressures to diatom assemblages using the $r b c L 312$ bp barcode, next-generation sequencing (MiSeq Illumina), and bioinformatic evaluation (Mothur Software). Statistical analysis was then applied to identify the environmental (i.e., river types, geo-morphological) and anthropogenic (i.e., physical, chemical, human landuse pressures) variables' role in the observed diatom diversity. The Indice de Polluosensibilité Spécifique (IPS) index was used as it was shown to better respond to pressures that affect water quality in Cyprus rivers (WDD, 2014). Results indicate differences in diatom assemblages between intermittent and perennial rivers. Achnanthidium minutissimum was more abundant in intermittent rivers; whereas Amphora pediculus and Planothidium victorii (P. caputium) in perennial ones. Furthermore, we could demonstrate the correlation between nutrients (e.g., nitrogen, phosphorus), characteristics of the individual sampling sites (e.g., elevation), and land use activities on the observed differences in diatom diversity (Pissaridou, 2021). Additionally, results were compared to the morphotaxonomy-based approach which was conducted microscopically. Results show a positive correlation between morphological and molecular IPS scores. Points deviating from the norm are influenced by the limitations of both techniques. Fistulifera saprophila had a key role in this observation, as it negatively influences IPS scores. All in all, we conclude that DNA metabarcoding complements the morphological methodology for the ecological quality assessment of freshwaters in Cyprus. Multi-stressors and anthropogenic pressures have a significant statistical relationship to the observed diatom diversity and play a pivotal role in determining Cyprus' rivers' ecological status (Fig. 1). 


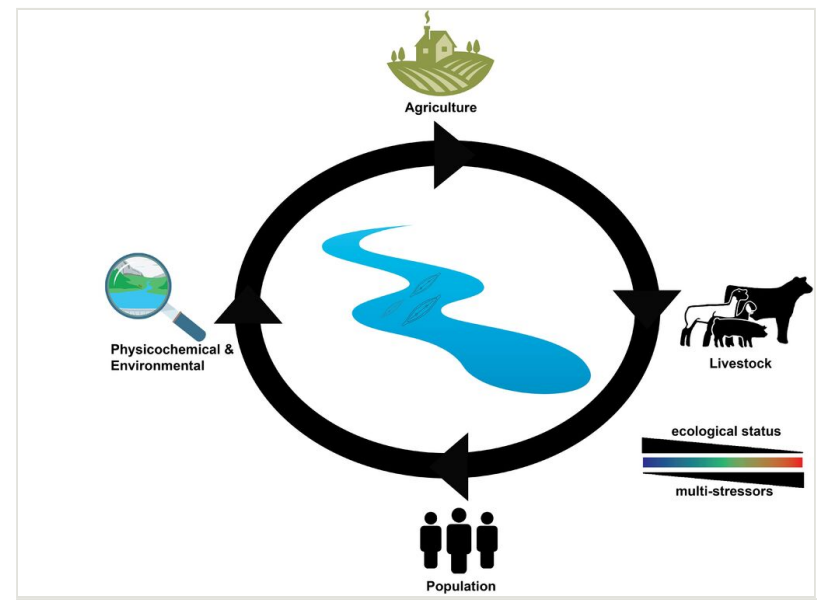

Figure 1. doi

Figure 1: Multi-stressors affect the ecological status of Cyprus' rivers.

Foster, D., Wood, A., Griffiths, M., 2000. The Water Framework Directive (2000/60/EC) An introduction Dave Foster - Policy Advisor (Europe), Aram Wood EP Scientist (Water), Dr Martin Griffiths - Head of Water Quality, Environment Agency, Head Office, Rio House, Waterside Drive, Aztec West, Almon 7-9.

Pissaridou, P., Vasselon V., Christou A., Chonova T., Lacroix S., Papatheodoulou A., Drakou K., Tziortzis I., Dörflinger G., Rimet F., Bouchez A. and Vasquez MI. 2021 Deciphering Cyprus' diatom diversity and the effects of environmental and anthropogenic influences for ecological assessment of rivers using DNA metabarcoding.Chemosphere (In Press)

Vasselon, V., Frédéric, R., Isabelle, D., Olivier, M., Yorick, R., Agnès, B., 2019. Assessing pollution of aquatic environments with diatoms' DNA metabarcoding: Experience and developments from France Water Framework Directive networks. Metabarcoding and Metagenomics 3, 101-115. https://doi.org/10.3897/mbmg.3.39646

WDD, 2014. Review and update of article 5 of Directive 2000/60/EC (Water reservoirs) \& Classification of water status (Rivers, natural lakes and water reservoirs), That will establish baseline information and data for the 2nd cyprus river basin management plan.

\section{Keywords}

diatom; ecological assessment; DNA metabarcoding; multiple pressure; intermittent; perennial 


\section{Presenting author}

Panayiota Pissaridou

\section{Presented at}

1st DNAQUA International Conference (March 9-11, 2021)

\section{Funding program}

This study was funded by the COST Action DNAqua-Net (CA15219), the Cyprus University of Technology, and the UMR CARRTEL - INRAE (National Research Institute for Agriculture, Food and Environment). The sample collection was partly performed within Contract No. WDD15/2017 «Sampling, Sample Analysis and Evaluation of Biological Quality Elements. Implementation of Article 8 of Directive 2000/60/E.C.». Contractor: I.A.CO Environmental \& Water Consultants Ltd. Contracting Authority: Water Development Department, Ministry of Agriculture, Rural Development and Environment, Republic of Cyprus. Finally, special thanks to Sonia Lacroix, who performed DNA libraries' preparation for all samples at the molecular laboratory of INRA CARRTEL.

\section{Author contributions}

Pissaridou P.: Validation, Formal analysis, Data Curation, Writing, Visualization, Vasselon V.: Methodology, Software, Christou A.: Investigation, Chonova T.: Data Curation, Validation, Papatheodoulou A.: Investigation, Drakou K.: Investigation, Methodology, Tziortzis I.: Resources, Dörflinger G.: Resources, Rimet F.: Supervision, Cantonati M.: Methodology, Supervision, Investigation, Data Curation, Bouchez A.: Supervision, Conceptualization, Funding and Vasquez MI: Supervision, Resources, Conceptualization, Funding.

\section{Conflicts of interest}

No Conflicts of interes 